\title{
Effect of Hall Currents, Thermal Radiation and Radiation Absorption on Mixed Convective Heat and Mass Transfer Flow Past a Stretching Sheet
}

\author{
*Dr. K. Sree Ranga Vani ${ }^{1}$, ${ }^{*}$ Prof.D.R.V.Prasada Rao ${ }^{2}$ \\ ${ }^{I}$ Department of Mathematics, Sri Sathya Sai Institute of Higher Learning, Ananthapuramu, A.P., India. \\ ${ }^{2}$ Department of Mathematics, Sri Krishnadevaraya University,Ananthapuramu, A.P.,India.
}

\begin{abstract}
In the present work we study the combined influence of chemical reaction, Hall currents and radiation absorption on convective heat and mass transfer flow of a viscous electrically conducting fluid past a stretching sheet. The equations governing the flow of heat and mass transfer have been solved by Galerkin finite element analysis with three nodded line segments. The velocity, temperature and concentration have been analysed for different values of $M, m, R, N, N_{l}, S c$ and $Q_{l}$. The rate of heat and mass transfer on the plate has been evaluated numerically for different variations.
\end{abstract}

Keywords: Hall Current, Chemical Reaction, Radiation absorption, Stretching sheet, Heat and Mass transfer.

\section{Introduction}

Laminar boundary layer behavior over a moving continuous and linearly stretching surface is a significant type of flow has considerable practical applications in engineering, electrochemistry (Chin [11], Gorla [17]) and polymer processing, (Griffith [18], Erickson et. al. [15]). For example, materials manufactured by extrusion process and heat treated materials traveling between a feed roll and a windup roll or on a conveyor belt possesses the characteristics of a moving continuous surface. The hydromagnetic flow and heat transfer problems have become important industrially. To be more specific, it may be pointed out that many metallurgical processes involve the cooling of continuous strips or filaments by drawing them through a quiescent fluid and that in the process of drawing, these strips are sometimes stretched. Mention may be made of drawing, annealing and tinning of copper wires. In all the cases the properties of the final product depend to a great extent on the rate of cooling. By drawing such strips in an electrically conducting fluid subjected to magnetic fluid, the rate of cooling can be controlled and a final product of desired characteristics can be achieved. Another interesting application of hydromagnetics to metallurgy lies in the purification of molten metals from nonmetallic inclusions by the application of a magnetic field. The study of heat and mass transfer is necessary for the determining the quantity of the final product. However, there are fluids, which react chemically with some other ingredients present in them. The effect of a chemical reaction on the flow past an impulsively started infinite vertical plate with uniform heat flux was studied by Das et.al. [14], Anderson et. al. [4], have studied the diffusion of a chemical reactive species from a linearly stretching sheet. Anjalidevi and Kandaswamy [5] have investigated the effect of a chemical reaction on the flow along a semi infinite horizontal plate in the presence of heat transfer. Anjalidevi and Kandaswamy [6] have studied the effect of a chemical reaction on the flow in the presence of heat transfer and magnetic filed. Muthukumaraswamy and Ganesan [26] have analyzed the effect of a chemical reaction on the unsteady flow past on impulsively started semi-infinite vertical plate, which is subject to uniform heat flux. McLeod and Rajagopal [24] have investigated the uniqueness of the flow of a Navier Stoke's fluid due to a linear stretching boundary. Raptis et. al. [29], have studied the viscous flow over a non-linearly stretched sheet in the presence of a chemical reaction and magnetic field.

In 1961, Sakiadis [31] who developed a numerical solution for the boundary layer flow field over a continuous solid surface moving with constant speed. Due to entertainment of ambient fluid, this boundary layer flow situation is quite different from the classical blasius problem over a semi-infinite flat plate. Suction or injection of a stretched surface was studied by Erickson et.al. [15], and Fox et.al. [16] for uniform velocity and temperature and investigates its effects on the heat and mass transfer in the boundary layer. Chen and Char [10] have studied the suction and injection on a linearly moving plate subject to uniform wall temperature and heat flux and the more general case using a power law velocity and temperature distribution at the surface was studied by Ali [3]. Magyari et.al. [23] have reported analytical and computational solution when the surface moves with rapidly decreasing velocities using the self-similar method. In all the papers mentioned above the effect of buoyancy force was relaxed. The above investigations having a definite bearing on the problem of a Polymer sheet extruded continuously from a dye. It is usually assumed that the sheet is in extensible, but situations may arise in the polymer industry in which it is necessary to deal with a stretching plastic sheet, as 
noted by Crane [13]. The study of heat generation or absorption in moving fluids is important in the problems dealing with chemical reactions and these concerned with dissociating distribution. Consequently, the practice deposition rate in nuclear reactors, electronic chips and semi conductor waves. Vajravelu and Hadjinicolaou [35] have studied the heat characteristics in the laminar boundary layer of a viscous fluid over a stretching sheet with viscous dissipation or frictional heating and internal heat generation. Mohebujjaman et.al. [25] have studied the MHD heat transfer mixed convection flow along a vertical stretching sheet in presence of magnetic field with heat generation. Sajid et.al. [30] have discussed the non-similar analytic solution for MHD flow and heat transfer in a third-order fluid over a stretching sheet. Biliana et.al. [7] have analyzed the numerical solution of the boundary layer flow over an exponentially stretching sheet with thermal radiation. Jat et.al. [22] have studied the MHD flow and heat transfer over a stretching sheet.

The effect of chemical reaction on free convective flow and mass transfer of a viscous, incompressible and electrically conducting fluid over a stretching sheet was investigated by Afify [2] in the presence of a transverse magnetic field. In all these investigations the electrical conductivity of the fluid was assumed to be uniform. However, in an ionized fluid where the density is low and/or magnetic field is very strong, the conductivity normal to the magnetic field is reduced due to the spiraling of electrons and ions about the magnetic lines of force before collisions take place and a current induced in a direction normal to both the electric and magnetic fields. This phenomenon available in the literature is known as Hall Effect. Thus the study of MHD viscous flows, heat and mass transfer with Hall currents has important bearing in the engineering applications.

Hall effect on MHD boundary layer flow over a continues semi-infinite flat plate moving with a uniform velocity in its own plane in an incompressible viscous and electrically conducting fluid in the presence of a uniform transverse magnetic field were investigated by Watanabe and Pop [37]. Abo-Eldahab [1] have investigated free convective flows past a semi-infinite vertical plate with mass transfer. The effect of Hall current on the study MHD flow of an electrically conducting, incompressible Burger's fluid between two parallel electrically insulating infinite plane was studied by Rana et. al. [28].

Samadh et. al. [32] have studied MHD heat and mass transfer free convection flow along a vertical stretching sheet in the presence of magnetic field with heat generation. Seddeek [33] have studied the heat and mass transfer on a stretching sheet with a magnetic field in a visco-elastic fluid flow through a porous medium with heat source or sink. Veena et.al. [36] have discussed the non-similar solutions for heat and mass transfer flow in an electrically conducting visco-elastic fluid over a stretching sheet embedded in a porous medium. Hsiao [16] has analysed the heat and mass transfer for electrical conducting mixed convection with radiation effect for visco-elastic fluid past a stretching sheet. Shit [34] has studied Hall effects on MHD free convective flow on mass transfer over a stretching sheet. Recently, Raghavendra Rao [27] has discussed the effect of chemical reaction, Hall effects on the convective heat and mass transfer flow past a stretching sheet.

\section{Formulation of the Problem}

We consider the steady flow of an incompressible, viscous ,electrically conducting fluid past a flat surface which is assuming from a horizontal slit on a vertical surface and is stretched with a velocity proportional to distance from a fixed origin $\mathrm{O}$. We choose a stationary frame of reference $\mathrm{O}(\mathrm{x}, \mathrm{y}, \mathrm{z})$ such that $\mathrm{x}$-axis is along the direction of motion of the stretching surface, $y$ axis is normal to this surface and z-axis is transverse to the xy-plane. A uniform magnetic field in the presence of fluid flow induces the current $\left(J_{x}, 0, J_{z}\right)$.

When the strength of the magnetic field is very large we include the Hall current so that the generalized Ohm's law (Cowling[12]) is modified to

$$
\bar{J}+\omega_{e} \tau_{e} \bar{J} x \bar{H}=\sigma\left(\bar{E}+\mu_{e} \bar{q} x \bar{H}\right)
$$

where $\bar{q}$ is the velocity vector. $\mathrm{H}$ is the magnetic field intensity vector. $\overline{\mathrm{E}}$ is the electric field, $\overline{\mathrm{j}}$ is the current density vector, $\omega_{\mathrm{e}}$ is the cyclotron frequency, $\tau_{\mathrm{e}}$ is the electron collision time, $\sigma$ is the fluid conductivity and $\mu_{e}$ is the magnetic permeability. The effect of Hall current give rise to a force in the z-direction which in turn produces a cross flow velocity in this direction and thus the flow becomes three -dimensional. To simplify the analysis, we assume that the flow quantities do not vary along z-direction

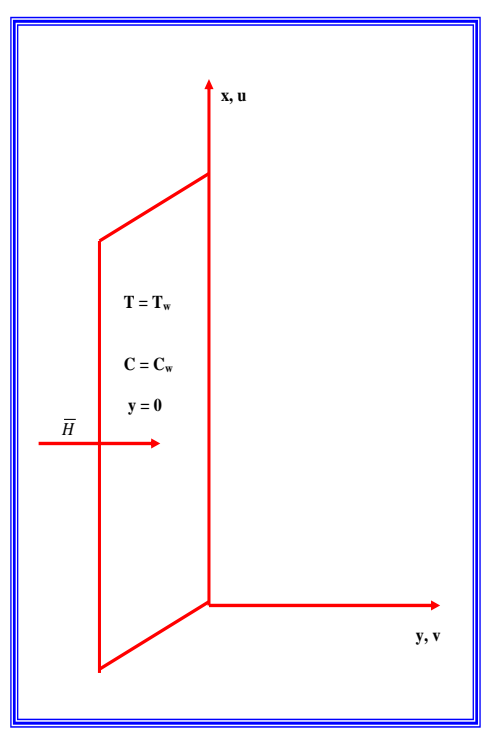

Fig. I and this will be valid if the surface is of very width along the $\mathrm{z}$-direction. Neglecting the electron pressure gradient, ion-slip and thermo-electric effects and assuming the electric field $\mathrm{E}=0$, equation (2.1) reduces

$$
j_{x}-m H_{0} J_{z}=-\sigma \mu_{e} H_{0} w
$$




$$
J_{z}+m H_{0} J_{x}=\sigma \mu_{e} H_{0} u
$$

where $\mathrm{m}=\omega_{e} \tau_{e}$ is the Hall parameter.

On solving equations (2)\&(3) we obtain

$$
\begin{aligned}
& j_{x}=-\frac{\sigma \mu_{e}^{2} H_{0}^{2}}{1+m^{2}}(m u-w) \\
& j_{z}=\frac{\sigma \mu_{e}^{2} H_{o}^{2}}{1+m^{2}}(u+m w)
\end{aligned}
$$

where $\mathrm{u}, \mathrm{w}$ are the velocity components along $\mathrm{x}$ and $\mathrm{z}$ directions respectively, The equation of Continuity is

$$
\frac{\partial u}{\partial x}+\frac{\partial v}{\partial y}=0
$$

The Momentum equations are

$$
\begin{aligned}
& u \frac{\partial u}{\partial x}+v \frac{\partial u}{\partial z}=-\frac{\partial p}{\partial x}+v \frac{\partial^{2} u}{\partial y^{2}}-\mu_{e} H_{0} J_{z}-\rho \bar{g} \\
& u \frac{\partial W}{\partial x}+v \frac{\partial W}{\partial y}=v \frac{\partial^{2} W}{\partial y^{2}}+\mu_{e} H_{0} J_{x}
\end{aligned}
$$

The energy equation is

$$
\rho C_{p}\left(u \frac{\partial T}{\partial x}+w \frac{\partial T}{\partial z}\right)=k_{f} \frac{\partial^{2} T}{\partial y^{2}}+\left(C-C_{\infty}\right)-\frac{\partial}{\partial y}\left(q_{r}\right)
$$

The diffusion equation is

$$
\left(u \frac{\partial C}{\partial x}+v \frac{\partial C}{\partial y}\right)=D \frac{\partial^{2} C}{\partial y^{2}}-k_{0}\left(C-C_{\infty}\right)
$$

The equation of state is

$$
\rho-\rho_{0}=-\beta\left(T-T_{\infty}\right)-\beta^{\bullet}\left(C-C_{\infty}\right)
$$

Substituting $\mathrm{J}_{\mathrm{x}}$ and $\mathrm{J}_{\mathrm{z}}$ from equations (4)\&(5)in equations (7)\&(8) we obtain

$$
\begin{aligned}
& u \frac{\partial u}{\partial x}+v \frac{\partial u}{\partial y}=+v \frac{\partial^{2} u}{\partial y^{2}}-\frac{\sigma \mu_{e} H_{0}^{2}}{1+m^{2}}(u+m w)+ \\
& +\beta g\left(T-T_{\infty}\right)+\beta^{\bullet} g\left(C-C_{\infty}\right) \\
& \left.u \frac{\partial w}{\partial x}+v \frac{\partial w}{\partial y}=v \frac{\partial^{2} w}{\partial y^{2}}\right)+\frac{\sigma u_{e}^{2} H_{0}^{2}}{1+m^{2}}\left(m_{0} u-w\right)
\end{aligned}
$$

Using Roseland approximation the radiative heat flux is given by

$$
q_{r}=\frac{-4 \sigma^{*}}{\beta_{R}} \frac{\partial}{\partial y}\left(T^{1^{4}}\right)
$$

And expanding $T^{1^{4}}$ about $\mathrm{T}_{\infty}$ by Taylor's expansion

$$
T^{1^{4}}=4 T_{\infty}^{3} T^{1}-3 T_{\infty}^{4}
$$

$$
\begin{aligned}
& \text { Using } \\
& \rho C_{p}\left(u \frac{\partial T}{\partial x}+w \frac{\partial T}{\partial z}\right)=k_{f} \frac{\partial^{2} T}{\partial y^{2}}+Q_{1}^{1}\left(C-C_{\infty}\right)+\frac{16 \sigma^{*} T_{\infty}^{3}}{3 \beta_{R}} \frac{\partial^{2} T}{\partial y^{2}}
\end{aligned}
$$

where $\mathrm{T}$ is the temperature and $\mathrm{C}$ is the concentration in the fluid. $\mathrm{k}_{\mathrm{f}}$ is the thermal conductivity, $\mathrm{Cp}$ is the specific heat at constant pressure, $\beta$ is the coefficient of thermal expansion, $\beta^{\bullet}$ is the volumetric expansion with concentration, $Q_{1}^{1}$ is the radiation absorption coefficient, $\mathrm{q}_{\mathrm{r}}$ is the radiative heat flux, $\mathrm{k}_{0}$ is the chemical reaction coefficient, $\mathrm{D}$ is the molecular viscosity, $\sigma^{*}$ is the Stephen Boltzmann constant, $\beta_{\mathrm{R}}$ is the mean absorption coefficient. 
The boundary conditions for this problem can be written as

$$
\begin{array}{ll}
u=b x, v=w=0, T=T_{w}, C=C_{w} & \text { at } y=0 \\
u=w=0, T=T_{\infty}, C=C_{\infty} & \text { as } y \rightarrow \infty
\end{array}
$$

Where $b>0$.The boundary conditions on the velocity in (2.17) are the no-slip conditions at the surface at $\mathrm{y}=0$, while the boundary conditions on the velocity as $y \rightarrow \infty$ follow from the fact that there is no flow far away from the stretching surface. The temperature and species concentration are maintained at a prescribed constant values $\mathrm{T}_{\mathrm{w}}$ and $\mathrm{C}_{\mathrm{w}}$ at the sheet and are assumed to vanish far away from the sheet.

On introducing the similarity variables

$$
\begin{aligned}
& \eta=\sqrt{\frac{b}{v}} y, \quad u=b x f^{\prime}(\eta), \quad v=-\sqrt{b v} f(\eta), \quad w=b x g(\eta) \\
& \theta(\eta)=\frac{T-T_{\infty}}{T_{w}-T_{\infty}}, \quad \phi(\eta)=\frac{C-C_{\infty}}{C_{w}-C_{\infty}}
\end{aligned}
$$

Equations (10), (12),(13) \& (16) reduces to

$$
\begin{aligned}
& f^{\prime \prime \prime}+f f^{\prime \prime}-f^{\prime 2}+G(\theta+N \phi)-\frac{M^{2}}{1+m^{2}}\left(f^{\prime}+m g\right)=0 \\
& g^{\prime \prime}+f g^{\prime}-\left(f^{\prime}+\frac{M^{2}}{1+m^{2}}\right) g+\frac{m M^{2}}{1+m^{2}} f^{\prime}=0 \\
& \theta^{\prime \prime}+P_{1} f \theta^{1}+Q_{1} N_{2} \phi=0 \\
& \phi^{\prime \prime}+S c\left(\phi^{\prime} f-\gamma \phi\right)=0
\end{aligned}
$$

and the boundary conditions (17)\&(18) are now obtained from (19) as

$$
\begin{aligned}
& f^{\prime}(0)=1, \quad f(0)=0, \quad \theta(0)=\phi(0)=0 \\
& f^{\prime}(\infty)=g(\infty)=\theta(\infty)=0
\end{aligned}
$$

where

$G=\frac{\beta g\left(T_{w}-T_{\infty}\right)}{b^{2} x}$ (Grashof number), $M^{2}=\frac{\sigma \mu_{e}^{2} H_{0}^{2}}{b x}$ (Hartmann number),

$N=\frac{\beta^{*}\left(C_{w}-C_{\infty}\right)}{\beta\left(T_{w}-T_{\infty}\right)}$ (Buoyancy ratio), $N_{1}=\frac{\beta_{R} v}{4 \sigma^{2} T_{\infty}^{3}}$ (Radiation parameter),

$Q_{1}=\frac{Q_{1}^{1}\left(C_{w}-C_{\infty}\right) k_{f}}{b\left(T_{w}-T_{\infty}\right) \nu}$ (Radiation absorption parameter), $S c=\frac{v}{D}$ (Schmidt number),

$\gamma=\frac{k_{0}}{b}$ (Chemical reaction parameter), $N_{2}=\frac{3 N_{1}}{3 N_{1}+4}, P_{1}=P N_{2}$

For the computational purpose and without loss of generality $\infty$ has been fixed as 8 . The whole domain is divided into 11 line elements of equal width, each element being three nodded.

\section{Finite Element Analysis}

The method basically involves the following steps:

(1) Division of the domain into elements, called the finite element mesh.

(2) Generation of the element equations using variational formulations.

(3) Assembly of element equations as in step 2.

(4) Imposition of boundary conditions to the equations obtained in step 3

(5) Solution of the assumed algebraic equations.

The assumed equations can be solved by any of the numerical technique viz. Gaussian elimination, LU Decomposition method etc.

Variational Formulation: The variational form associated with the equations(20)-(23)over a typical two nodded line at element $\left(\eta_{e}, \eta_{e+1}\right)$ is given by 


$$
\begin{aligned}
& \int_{\eta_{e}}^{\eta_{e+1}} w_{1}\left(f^{\prime}-h\right) d \eta=0 \\
& \int_{\eta_{e}}^{\eta_{e+1}} w_{12}\left(h^{\prime \prime}+f h^{\prime}-h^{2}+G(\theta+N \phi)-\frac{M^{2}}{1+m^{2}}(h+m g) d \eta=0\right. \\
& \int_{\eta_{e}}^{\eta_{e+1}} w_{3}\left(g^{\prime \prime}+f g^{\prime}-\left(h+\frac{M^{2}}{1+m^{2}}\right) g+\frac{m M^{2}}{1+m^{2}} h\right) d \eta=0 \\
& \int_{\eta_{e}}^{\eta_{e+1}} w_{4}\left(\theta^{\prime \prime}+P_{1} f \theta^{\prime}+Q_{1} N_{2} \phi\right) d \eta=0 \\
& \int_{\eta_{e}}^{\eta_{e+1}} w_{5}\left(\phi^{\prime \prime}+S c\left(\phi^{\prime} f-\gamma \phi\right)\right) d \eta=0
\end{aligned}
$$

Where w1, w2, w3, w4, w5 are arbitrary test functions and may be regarded as the variations in f, h, g, $\theta$ and $\phi$ respectively.

Finite Element Formulation: The finite element method may be obtained from (26)-(30) by substituting finite element approximations of the form

$f=\sum_{k=1}^{3} f_{k} \psi_{k}, \quad h=\sum_{k=1}^{3} h_{k} \psi_{k}, g=\sum_{k=1}^{3} g_{k} \psi_{k}, \theta=\sum_{k=1}^{3} \theta_{k} \psi_{k}, \phi=\sum_{k=1}^{3} \phi_{k} \psi_{k}$

We take $\mathrm{w} 1=\mathrm{w} 2=\mathrm{w} 3=\mathrm{w} 4=\mathrm{w} 5=\psi_{i}^{j}(i, j=1,2,3)$

Using (32) we can write equations (26) - (30) as

$$
\begin{aligned}
& \int_{\eta_{e}}^{\eta_{e+1}}\left(\frac{d f}{d \eta}-h\right) \psi_{i}^{j} d \eta=0 \\
& \int_{\eta_{e}}^{\eta_{e+1}}\left(\frac{d}{d \eta}\left(\frac{d h}{d \eta}\right)+f\left(\frac{d h}{d \eta}\right)-h^{2}+G(\theta+N \phi)-\frac{M^{2}}{1+m^{2}}(h+m g)\right) \psi_{i}^{j} d \eta=0 \\
& \left.\int_{\eta_{e}}^{\eta_{e+1}} \frac{d}{d \eta}\left(\frac{d g}{d \eta}\right)+f\left(\frac{d g}{d \eta}\right)-\left(h+\frac{M^{2}}{1+m^{2}}\right) g+\frac{m M^{2}}{1+m^{2}} h\right) \psi_{i}^{j} d \eta=0 \\
& \int_{\eta_{e}}^{\eta_{e+1}}\left(\frac{d}{d \eta}\left(\frac{d \theta}{d \eta}\right)+P_{1} f\left(\frac{d \theta}{d \eta}\right)\right) \psi_{i}^{j} d \eta+Q_{1} N_{2} \int_{\eta_{e}}^{\eta_{e+1}} \phi \psi_{i}^{j} d \eta=0 \\
& \int_{\eta_{e}}^{\eta_{e+1}}\left(\frac{d}{d \eta}\left(\frac{d \phi}{d \eta}\right)+S c\left(\left(\frac{d \phi}{d \eta}\right) f-\gamma \phi\right)\right) \psi_{i}^{j} d \eta=0
\end{aligned}
$$

\section{Stiffness matrices:}

The global matrix for $\theta$ is $\mathrm{A}_{3} \mathrm{X}_{3}=\mathrm{B}_{3}$ The global matrix for $\phi$ is $\mathrm{A}_{4} \mathrm{X}_{4}=\mathrm{B}_{4}$ The global matrix for $\mathrm{h}$ is $\mathrm{A}_{5} \mathrm{X}_{5}=\mathrm{B}_{5}$ The global matrix for $\mathrm{f}$ is $\mathrm{A}_{6} \mathrm{X}_{6}=\mathrm{B}_{6}$ The global matrix for $\mathrm{g}$ is $\mathrm{A}_{7} \mathrm{X}_{7}=\mathrm{B}_{7}$

Particular Cases:

1. In the absence of radiation absorption $\left(\mathrm{Q}_{1}=0\right)$ the results are good agreeing with Raghavendra Rao [27].

2. In the absence of thermal radiation $\left(\mathrm{N}_{1}=0\right)$, radiation absorption $\left(\mathrm{Q}_{1}=0\right)$ the results are in agreeing with Shit [34]. 


\section{Discussion of the Numerical Results}

We analyse the effect of chemical reaction, thermal radiation and radiation absorption on convective heat and mass transfer flow of a viscous, electrically conducting fluid part a stretching sheet. The non - linear coupled equations are solved by using a finite element technique with three nodded line segments.

The axial velocity $\left(\mathrm{f}^{1}(\eta)\right)$ is exhibited in figure 1 for different values of $\mathrm{m}$. From fig (1) we notice that the axial velocity enhances with Hall parameter $(m)$. The variation of $f^{1}(\eta)$ with radiation parameter $R$ reveals that higher the radiative heat flux smaller $\left|f^{1}(\eta)\right|$ in the flow region (fig 6). The variation of $f^{1}(\eta)$ with chemical reaction parameter $\gamma$ shows that $\left|f^{1}(\eta)\right|$ depreciates both in the degenerating and generating chemical reaction cases (fig 11). Also higher the radiation absorption parameter $\mathrm{Q}_{1}$ larger $\left|\mathrm{f}^{1}(\eta)\right|$ in the region (fig 16).

The transverse velocity $(f(\eta))$ is exhibited in figure 2 for different values of $m$. An increase in the Hall parameter $m$ results in an enhancement in $f(\eta)$. The variation of $f$ with radiation parameter $R$ is exhibited in fig (7). It is observed that higher the radiative heat flux lesser the transverse velocity. With respect to chemical reaction parameter $\gamma$, we notice that the transverse velocity depreciates with $\gamma$ both in the degenerating and generating chemical reaction cases (fig 12). An increase in the radiation absorption parameter $\mathrm{Q}_{1}$ results in an enhancement in $\mathrm{f}(\eta)$ in the entire flow region (fig 17).

The cross velocity $(g(\eta))$ is exhibited in figure 3 for different values of $\mathrm{m}$. $\mathrm{g}$ | enhances with increase in Hall parameter $\mathrm{m} \leq 1.5$ and depreciates with $\mathrm{m} \geq 2.5$ (fig 3 ). An increase in radiation parameter $\mathrm{R}$ leads to depreciation in $|\mathrm{g}|$ (figs 8). $|\mathrm{g}|$ experiences a depreciation with increase in the chemical reaction parameter $|\gamma|$ (fig 13). It is found that $|\mathrm{g}|$ enhances with increase in $\mathrm{Q}_{1}$ (figs 18).

The non - dimensional temperature $(\theta)$ is shown in figure 4 for different values of $\mathrm{m}$. We follow the convention that the non - dimensional temperature is positive or negative according as the actual temperature (T) is greater / lesser than Too. It is found that higher the Hall parameter (m) or radiative heat flux (figs 5, 9) smaller the actual temperature. The actual temperature enhances with increase in the chemical reaction parameter $|\gamma|$ or radiation absorption parameter $\mathrm{Q}_{1}$ in the entire flow region (figs. 14 \& 19).

The concentration distribution $(\phi)$ is shown in figure 5for different values of $\mathrm{m}$. We follow the convention that the non - dimensional concentration is positive or negative according as the actual concentration is greater / lesser than $\mathrm{C} \infty$. An increase in $\mathrm{m}$ or $\gamma$ or $\mathrm{Q}_{1}$ leads to a depreciation in the actual concentration (figs 5, $15 \& 20$ ). Higher the radiative heat flux larger the concentration in the flow region (fig 10).
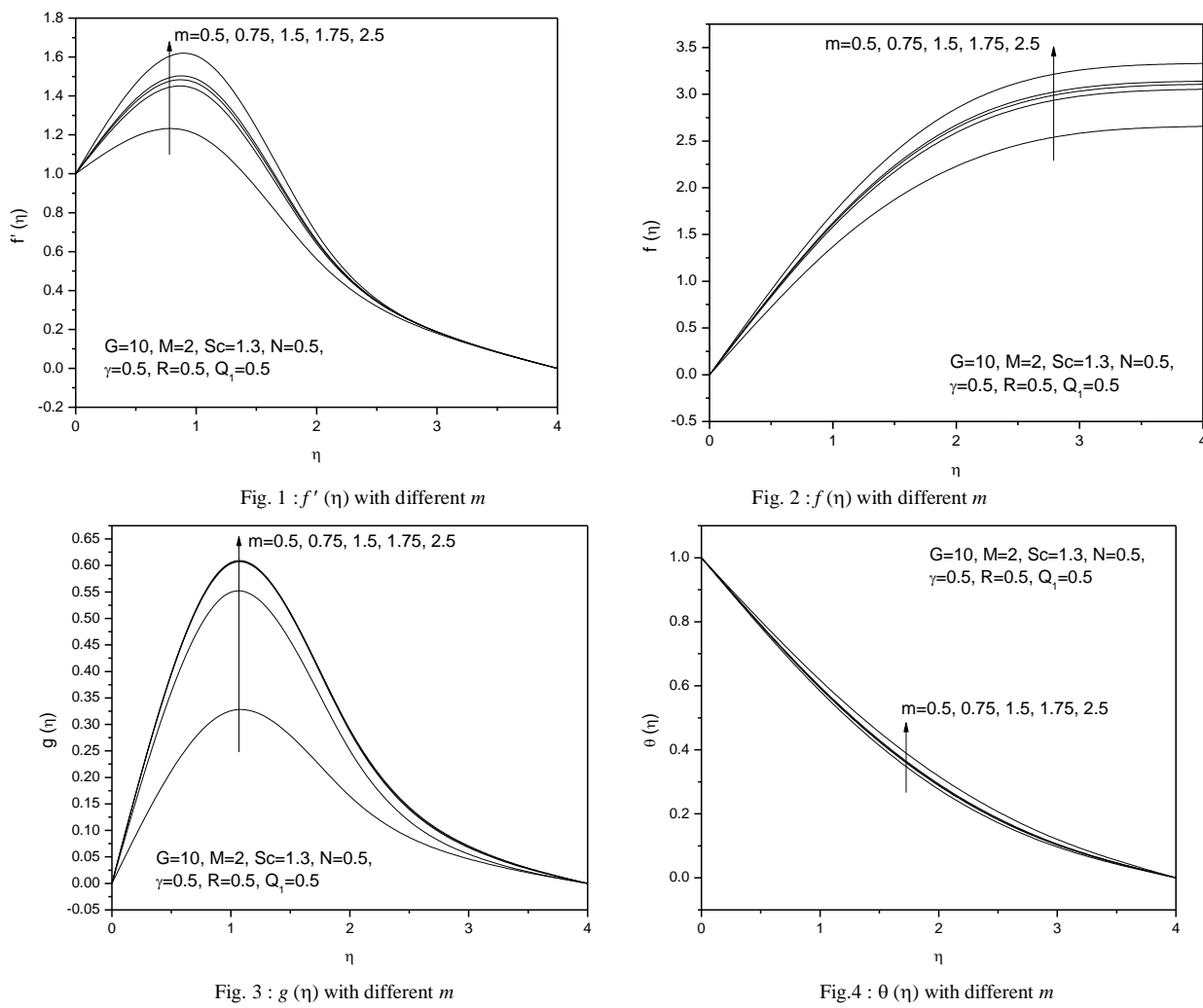

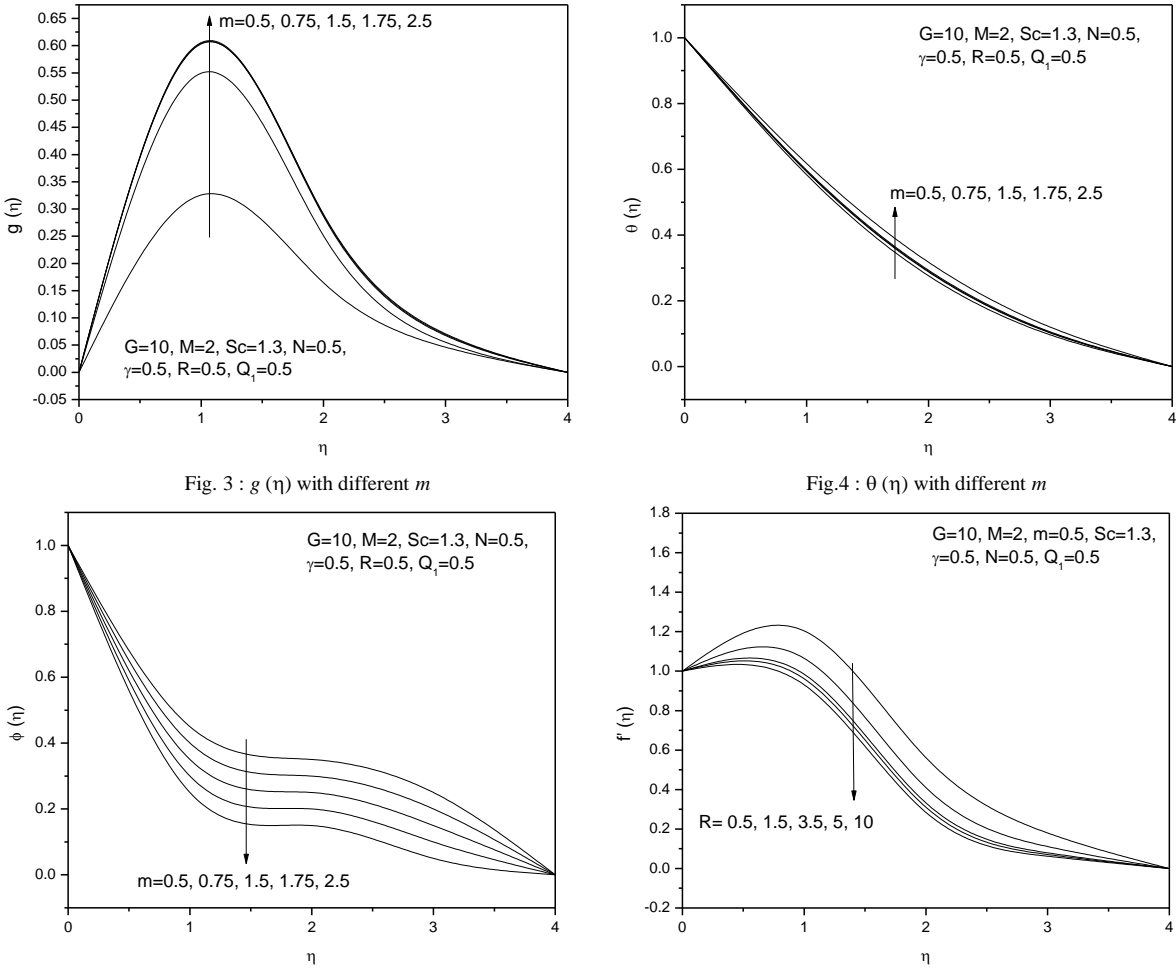

Fig. $5: \phi(\eta)$ with different $m$

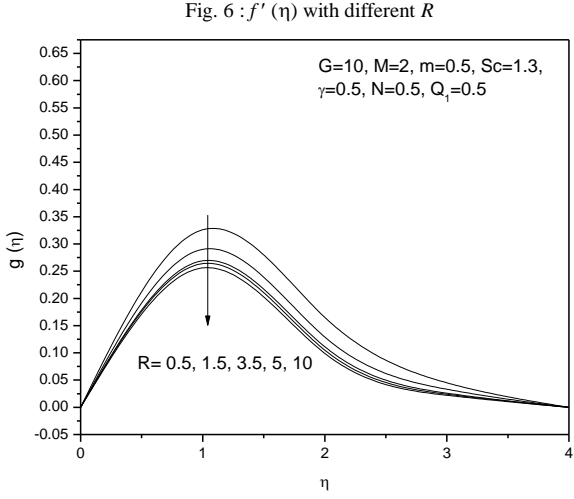

Fig. $7: f(\eta)$ with different $R$

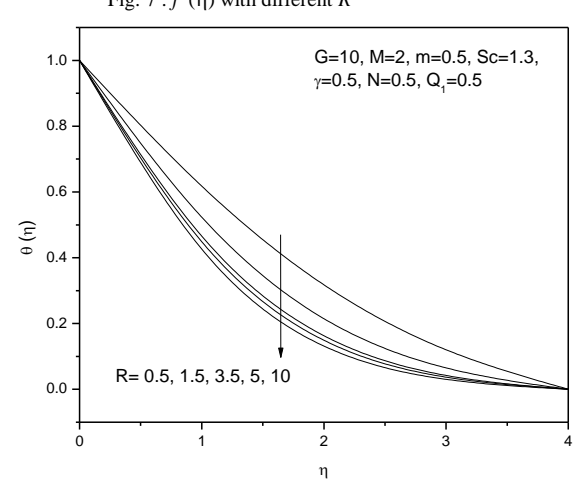

Fig. $9: \theta(\eta)$ with different $R$



Fig. $10: \phi(\eta)$ with different $R$ 

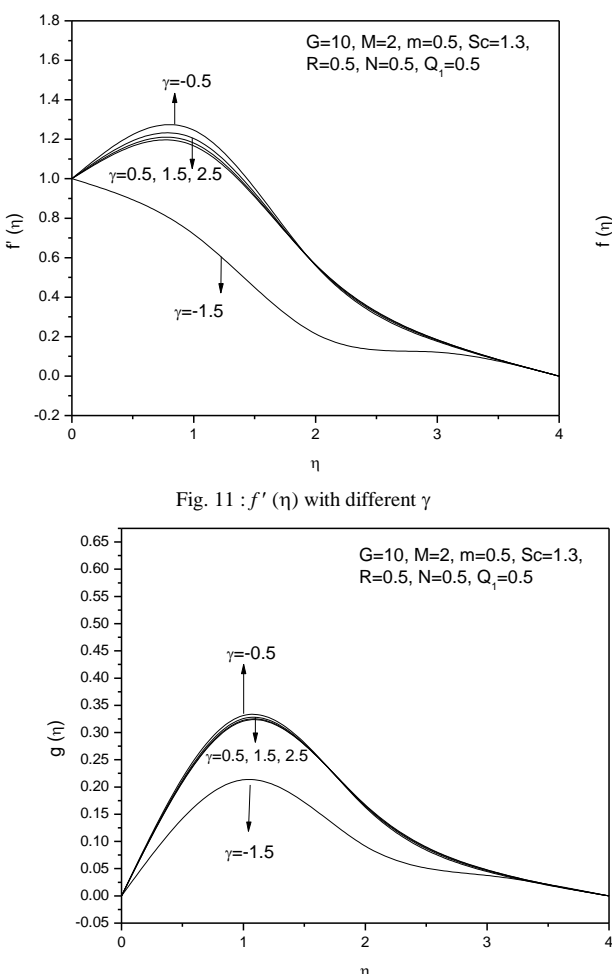

Fig. $13: g(\eta)$ with different $\gamma$

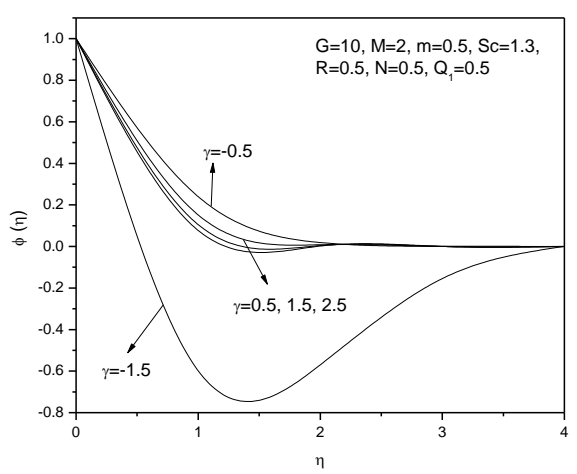

Fig. $15: \phi(\eta)$ with different $\gamma$

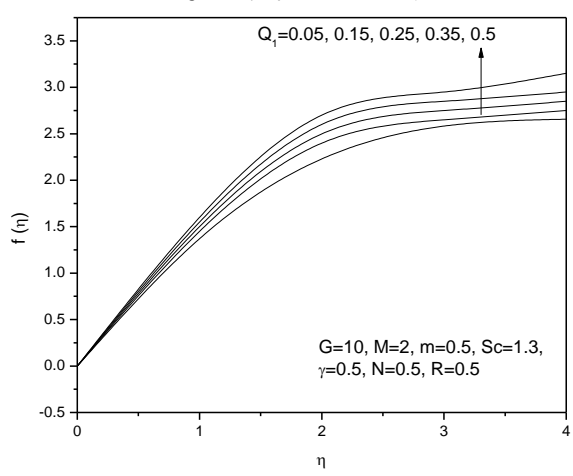

Fig. $17: f(\eta)$ with different $Q_{1}$

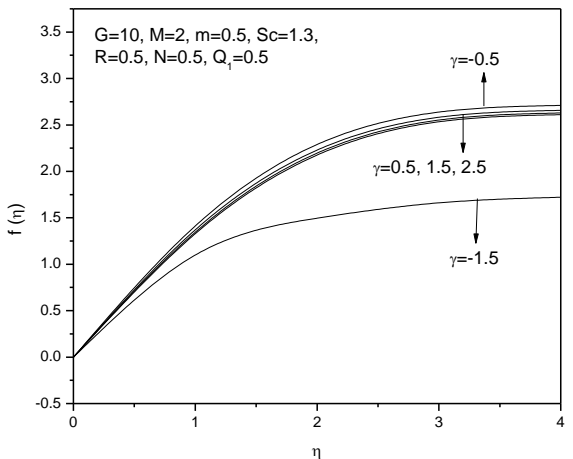

Fig. $12: f(\eta)$ with different $\gamma$

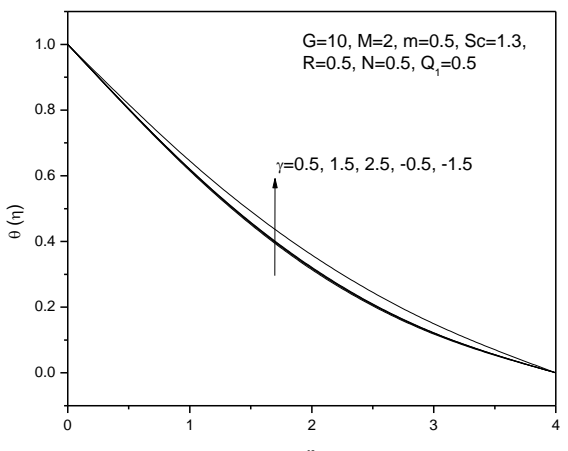

Fig. $14: \theta(\eta)$ with different $\gamma$

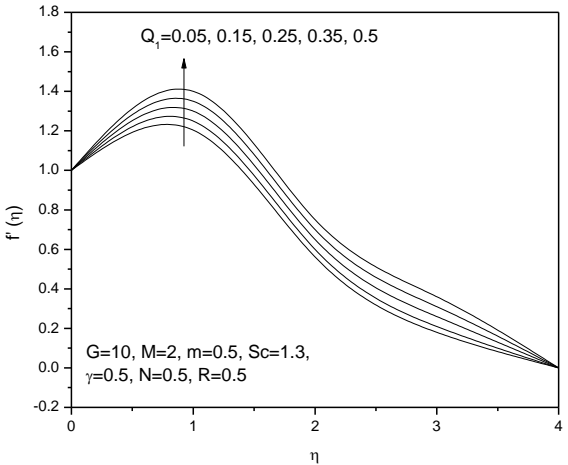

Fig. $16: f^{\prime}(\eta)$ with different $Q_{1}$

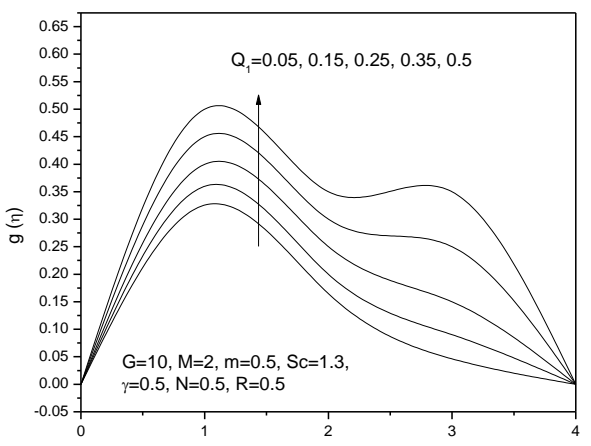

Fig. $18: g(\eta)$ with different $Q_{1}$ 

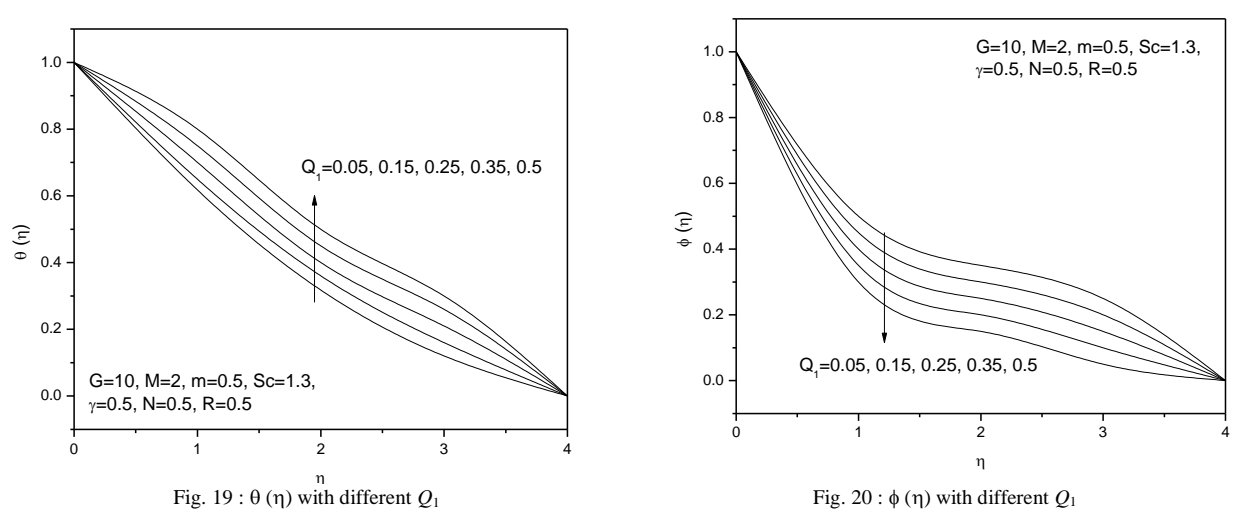

The stress component $\left(\tau_{\mathrm{x}}\right)$ is shown in tables $5.1 \& 5.2$ for different values. It is found that $\left|\tau_{\mathrm{x}}\right|$ at $\eta=0$ enhances with increase in $\mathrm{G}$ or $\mathrm{m}$ and reduces with $\mathrm{M}$. Higher the radiative heat flux or lesser the molecular diffusivity smaller $\left|\tau_{\mathrm{x}}\right|$. It enhances with increase in the buoyancy ratio $|\mathrm{N}|$ irrespective of the directions of the buoyancy forces. $\left|\tau_{x}\right|$ depreciates with increase in the chemical reaction parameter $\gamma$ and enhances with $\mathrm{Q}_{1}$.

The stress component $\left(\tau_{z}\right)$ at $\eta=0$ is shown in tables $5.3 \& 5.4$ for different values. $\left|\tau_{z}\right|$ enhances with increase in $\mathrm{G}$ or $\mathrm{Q}_{1}$ and reduces with $\mathrm{M}$. An increase in Sc or radiation parameter $\mathrm{R}$ leads to a depreciation in | $\tau_{z} \mid$. It enhances with increase in the Hall parameter $m \leq 1.5$ and reduces with $m \geq 2.5$. With respect to $\gamma$ we find that $\left|\tau_{z}\right|$ enhances in both the degenerating and generating chemical reaction cases.

The rate of heat transfer (Nusselt number) at $\eta=0$ is depicted in tables $5.5 \& 5.6$. The rate of heat transfer enhances with increase in $\mathrm{G}$ or radiation parameter $\mathrm{R}$ or Hall parameter $\mathrm{m}$. $|\mathrm{Nu}|$ reduces with $\mathrm{M}$ or $\mathrm{Q}_{1}$. With respect to buoyancy ratio $\mathrm{N}$ we find that $|\mathrm{Nu}|$ enhances with $\mathrm{N}>0$ and reduces with $|\mathrm{N}|(<0)$. Also $|\mathrm{Nu}|$ depreciates in both the degenerating and generating chemical reaction cases.

The rate of mass transfer (Sherwood number) at $\eta=0$ is shown in tables $5.7 \& 5.8$ for different variations. It is found that higher the thermal buoyancy parameter $\mathrm{G}$ or Hall parameter $\mathrm{m}$ or lesser the molecular diffusivity larger $|\mathrm{Sh}|$ at $\eta=0$. With respect to $\mathrm{N}$ we find that $|\mathrm{Sh}|$ enhances with $\mathrm{N}>0$ when the buoyancy forces act in the same direction and depreciates with $|N|(<0)$ when they act in opposite directions. Higher the Lorentz force or radiative heat flux lesser $|\mathrm{Sh}|$ at $\eta=0$. $|\mathrm{Sh}|$ experiences an enhancement in both degenerating and generating chemical reaction cases. Also it enhances with radiation absorption parameter $\mathrm{Q}_{1}$.

Table 1: Shear stress $\left(\tau_{\mathrm{x}}\right)$

\begin{tabular}{|l|l|l|l|l|l|l|}
\hline $\mathrm{G}$ & $\mathrm{I}$ & II & III & IV & V & VI \\
\hline $10^{2}$ & 2.85197 & -3.8358 & -4.3969 & -2.68534 & -2.55014 & -2.50797 \\
\hline $3 \times 10^{2}$ & -7.01125 & -8.2517 & -8.9005 & -6.65115 & -6.37879 & -6.29641 \\
\hline $5 \times 10^{2}$ & -10.7935 & -12.2086 & -12.9112 & -10.2489 & -9.85054 & -9.73162 \\
\hline $\mathrm{m}$ & 0.5 & 1.5 & 2.5 & 0.5 & 0.5 & 0.5 \\
\hline $\mathrm{R}$ & 0.5 & 0.5 & 0.5 & 1.5 & 5 & 10 \\
\hline
\end{tabular}

Table 2: Shear stress $\left(\tau_{x}\right)$

\begin{tabular}{|l|l|l|l|l|l|l|l|l|}
\hline $\mathrm{G}$ & $\mathrm{I}$ & $\mathrm{II}$ & $\mathrm{III}$ & $\mathrm{IV}$ & $\mathrm{V}$ & $\mathrm{VI}$ & $\mathrm{VII}$ & $\mathrm{VIII}$ \\
\hline $10^{2}$ & 2.85197 & -2.7514 & -2.67849 & -3.00894 & -2.28797 & -2.97089 & -2.86102 & -2.89243 \\
\hline $3 \times 10^{2}$ & -7.01125 & -6.8734 & -6.76547 & -7.19841 & -5.4362 & -5.89073 & -7.02324 & -7.0649 \\
\hline $5 \times 10^{2}$ & -10.7935 & -10.6312 & -10.4992 & -11.001 & -8.37414 & -8.45327 & -10.8073 & -10.8555 \\
\hline$\gamma$ & 0.5 & 1.5 & 2.5 & -0.5 & -1.5 & -2.5 & 0.5 & 0.5 \\
\hline $\mathrm{Q}_{1}$ & 0.5 & 0.5 & 0.5 & 0.5 & 0.5 & 0.5 & 1 & 2 \\
\hline
\end{tabular}

Table 3: Shear stress $\left(\tau_{\mathrm{z}}\right)$

\begin{tabular}{|l|l|l|l|l|l|l|}
\hline $\mathrm{G}$ & $\mathrm{I}$ & $\mathrm{II}$ & $\mathrm{III}$ & $\mathrm{IV}$ & $\mathrm{V}$ & $\mathrm{VI}$ \\
\hline $10^{2}$ & 1.00312 & 1.6379 & 1.4399 & 0.956163 & 0.919628 & 0.908569 \\
\hline $3 \times 10^{2}$ & 1.33175 & 2.05702 & 1.7385 & 1.24916 & 0.72749 & 1.17184 \\
\hline $5 \times 10^{2}$ & 1.56724 & 2.33636 & 1.9362 & 1.45853 & 0.81201 & 1.36064 \\
\hline $\mathrm{m}$ & 0.5 & 1.5 & 2.5 & 0.5 & 0.5 & 0.5 \\
\hline $\mathrm{R}$ & 0.5 & 0.5 & 0.5 & 1.5 & 5 & 10 \\
\hline
\end{tabular}

Table 4: Shear stress $\left(\tau_{z}\right)$

\begin{tabular}{|l|l|l|l|l|l|l|l|l|}
\hline $\mathrm{G}$ & $\mathrm{I}$ & $\mathrm{II}$ & $\mathrm{III}$ & IV & V & VI & VII & VIII \\
\hline $10^{2}$ & 1.00312 & 0.99082 & 0.982389 & 1.02359 & 0.844269 & 0.983303 & 1.00474 & 1.01032 \\
\hline $3 \times 10^{2}$ & 1.33175 & 1.31975 & 1.3107 & 1.34863 & 0.98211 & 1.11396 & 1.3333 & 1.3383 \\
\hline $5 \times 10^{2}$ & 1.56724 & 1.55586 & 1.5468 & 1.58218 & 1.08569 & 1.18898 & 1.56873 & 1.57391 \\
\hline$\gamma$ & 0.5 & 1.5 & 2.5 & -0.5 & -1.5 & -2.5 & 0.5 & 0.5 \\
\hline
\end{tabular}




\begin{tabular}{|l|l|l|l|l|l|l|l|l|}
\hline $\mathrm{Q}_{1}$ & 0.5 & 0.5 & 0.5 & 0.5 & 0.5 & 0.5 & 1 & 2 \\
\hline
\end{tabular}

Table 5: Nusselt number $(\mathrm{Nu})$

\begin{tabular}{|l|l|l|l|l|l|l|}
\hline $\mathrm{G}$ & $\mathrm{I}$ & $\mathrm{II}$ & $\mathrm{III}$ & $\mathrm{IV}$ & $\mathrm{V}$ & VI \\
\hline $10^{2}$ & 0.39443 & 0.417884 & 0.43398 & 0.507329 & 0.60428 & 0.635659 \\
\hline $3 \times 10^{2}$ & 0.46167 & 0.488 & 0.503187 & 0.608655 & 0.727497 & 0.765014 \\
\hline $5 \times 10^{2}$ & 0.51103 & 0.53789 & 0.55212 & 0.6795 & 0.81201 & 0.85342 \\
\hline $\mathrm{m}$ & 0.5 & 1.5 & 2.5 & 0.5 & 0.5 & 0.5 \\
\hline $\mathrm{R}$ & 0.5 & 0.5 & 0.5 & 1.5 & 5 & 10 \\
\hline
\end{tabular}

Table 6: Nusselt number $(\mathrm{Nu})$

\begin{tabular}{|l|l|l|l|l|l|l|l|l|}
\hline $\mathrm{G}$ & $\mathrm{I}$ & $\mathrm{II}$ & $\mathrm{III}$ & $\mathrm{IV}$ & $\mathrm{V}$ & $\mathrm{VI}$ & $\mathrm{VII}$ & VIII \\
\hline $10^{2}$ & 0.39443 & 0.392969 & 0.392019 & 0.39699 & 0.366152 & 0.388074 & 0.382029 & 0.338803 \\
\hline $3 \times 10^{2}$ & 0.46167 & 0.45995 & 0.45869 & 0.46418 & 0.387129 & 0.416123 & 0.451119 & 0.414285 \\
\hline $5 \times 10^{2}$ & 0.51103 & 0.50928 & 0.507924 & 0.513399 & 0.40063 & 0.427613 & 0.501462 & 0.468054 \\
\hline$\gamma$ & 0.5 & 1.5 & 2.5 & -0.5 & -1.5 & -2.5 & 0.5 & 0.5 \\
\hline $\mathrm{Q}_{1}$ & 0.5 & 0.5 & 0.5 & 0.5 & 0.5 & 0.5 & 1 & 2 \\
\hline
\end{tabular}

Table 7: Sherwood number (Sh)

\begin{tabular}{|l|l|l|l|l|l|l|}
\hline $\mathrm{G}$ & $\mathrm{I}$ & $\mathrm{II}$ & $\mathrm{III}$ & $\mathrm{IV}$ & $\mathrm{V}$ & VI \\
\hline $10^{2}$ & 1.29856 & 1.3501 & 1.3821 & 1.28057 & 1.26577 & 1.26114 \\
\hline $3 \times 10^{2}$ & 1.45556 & 1.5086 & 1.5313 & 1.42688 & 1.40455 & 1.39772 \\
\hline $5 \times 10^{2}$ & 1.56816 & 1.6204 & 1.6468 & 1.53211 & 1.50489 & 1.49665 \\
\hline $\mathrm{m}$ & 0.5 & 1.5 & 2.5 & 0.5 & 0.5 & 0.5 \\
\hline $\mathrm{R}$ & 0.5 & 0.5 & 0.5 & 1.5 & 5 & 10 \\
\hline
\end{tabular}

Table 8: Sherwood number (Sh)

\begin{tabular}{|l|l|l|l|l|l|l|l|l|}
\hline $\mathrm{G}$ & $\mathrm{I}$ & $\mathrm{II}$ & $\mathrm{III}$ & $\mathrm{IV}$ & $\mathrm{V}$ & $\mathrm{VI}$ & $\mathrm{VII}$ & VIII \\
\hline $10^{2}$ & 1.29856 & 1.70438 & 2.0393 & 0.75723 & 1.65046 & 0.150344 & 1.29928 & 1.30177 \\
\hline $3 \times 10^{2}$ & 1.45556 & 1.81499 & 2.12427 & 1.01687 & 2.48687 & 1.91216 & 1.45625 & 1.45866 \\
\hline $5 \times 10^{2}$ & 1.5681 & 1.90034 & 2.19266 & 1.17753 & 2.87801 & 2.74116 & 1.56866 & 1.57093 \\
\hline$\gamma$ & 0.5 & 1.5 & 2.5 & -0.5 & -1.5 & -2.5 & 0.5 & 0.5 \\
\hline $\mathrm{Q}_{1}$ & 0.5 & 0.5 & 0.5 & 0.5 & 0.5 & 0.5 & 1 & 2 \\
\hline
\end{tabular}

\section{Conclusions}

* The axial velocity, the actual temperature and the actual concentration depreciates and enhances the secondary velocity with an enhancement in Hall parameter. $|\mathrm{g}|$ enhances with increase in Hall parameter $\mathrm{m}$ $\leq 1.5$ and depreciates with $m \geq 2.5$.

* Higher the radiative heat flux smaller $\left|f^{1}(\eta)\right|, f(\eta),|g(\eta)|, \theta$ and larger $\phi$ in the flow region.

* $\left|\mathrm{f}^{\mathrm{f}}(\eta)\right|, \mathrm{f}(\eta)$ depreciates with $\gamma$ both in the degenerating and generating chemical reaction cases. $|\mathrm{g}|, \phi$ experiences a depreciation, the actual temperature enhances with increase in the chemical reaction parameter $|\gamma|$.

* Higher the radiation absorption parameter $\mathrm{Q}_{1}$, larger $\left|\mathrm{f}^{1}(\eta)\right|, \mathrm{f}(\eta),|\mathrm{g}(\eta)|, \theta$ and depreciates $\phi$ in the region.

* Higher the radiative heat flux (R), $\left|\tau_{\mathrm{x}}\right|,\left|\tau_{\mathrm{z}}\right|,|\mathrm{Sh}|$ depreciates and $|\mathrm{Nu}|$ enhances.

* $\left|\tau_{\mathrm{x}}\right|$ depreciates with increase in the chemical reaction parameter $\gamma .\left|\tau_{\mathrm{z}}\right|,|\mathrm{Sh}|$ enhances, $|\mathrm{Nu}|$ depreciates in both the degenerating and generating chemical reaction cases.

* $\left|\tau_{\mathrm{x}}\right|,\left|\tau_{\mathrm{z}}\right|$, $|\mathrm{Sh}|$ enhances, $|\mathrm{Nu}|$ reduces with radiation absorption parameter $\mathrm{Q}_{1}$.

\section{References}

[1] Abo-Eldahab, E.M and Elbarbary, E.M.E : Hall current effect on magnetohydrodynamic free convection flow past a semi-infinite vertical plate with mass transfer. Int. J. Eng. Sci., Vol.39, pp. 1641-1652 (2001).

[2] Afify, A.A : MHD free-convective flow and mass transfer over a stretching sheet with chemical reaction. Int. J. Heat Mass transfer. Vol.40, pp.495-500 (2004)

[3] Ali, M.E : On thermal boundary layer on a power-law stretched surface with suction or injection. Int. J. Heat Fluid Flow, Vol.16, No.4,pp.280-290 (1995).

[4] Anderson, H.I, Hansen, O.R and Holmedal, B : Diffusion of a Chemically reactive species from a stretching sheet. Int. J. Heat \& Mass Transfer, pp. 37-659 (1994).

[5] Anjalidevi, S.P. and Kandaswamy, R : Effects of chemical reaction heat and mass transfer on laminar flow along a semi infinite horizontal plate. Heat Mass Transfer, pp. 35-465 (1999).

[6] Anjalidevi, S.P. and Kandaswamy, R : Effects of chemical reaction heat and mass transfer on MHD flow past a semi infinite plate, Z. Angew. Math. \& Mech., pp. 80-697 (2000).

[7] Biliana, B, Roslinda, N : Numerical solution of the boundary layer flow over an exponentially stretching sheet with thermal radiation. European journal of Scientific Research, Vol.33, N0.4, pp.710-717(2009).

[8] Carragher, P, Crane, L.J : Heat transfer on continuous stretching sheet. Z. Angrew Math Mech, V.62, pp.564-565 (1982).

[9] Chakrabarthi, A, Gupta, A.S : Hydromagnetic flow heat and mass transfer over a stretching sheet. Quart. Appl. Math. V.33, pp.7378 (1979). 
[10] Chen, C.K and Char, M.I : Heat transfer of a continuous stretching surface with suction or blowing. J. Math. Ana. Appl., Vol.135, pp. 568-580 (1988).

[11] Chin, D.T : Mass transfer to a continuous moving sheet electrode. J. Electrochem. Soc., pp.122-643 (1975)

[12] Cowling T.G : Magnetohydrodynamics, Interscience Publishers, New York (1975).

[13] Crane, L.J : Flow past a stretching sheet. Zeitschrift Angewandt Mathematik and Physik, pp:21-26 (1970).

[14] Das, U.N, Deka, R.K and Soundalgekar, V.M : Effects of mass transfer on flow past an impulsively started infinite vertical plate with constant heat flux and chemical reaction. Forsch. Ingenieurwes, pp : 60-284 (1994).

[15] Erickson, L.E, Fan, L.T and Fox, V.G : Heat and mass transfer on a moving continuous flat plate with suction or injection. Indust. Eng. Chem. Fundamentals, pp.5-19 (1966).

[16] Fox, V.G, Erickson, L.E and Fan, L.T : Methods for solving the boundary layer equations for moving continuous flat surfaces with suction and injection. AICHE J., Vol.14, pp.726-736 (1968).

[17] Gorla, R.S.R., 1978. Unsteady mass transfer in the boundary layer on continuous moving sheet electrode, J. Electrochem. Soc., pp : $125-865$.

[18] Griffith, R.M : Velocity, Temperature and Concentration distribution during fibre spinning. Ind. Eng. Chem. Fund., pp.3-245 (1964).

[19] Grubka, L.J , Crane, L.J : Heat transfer characteristics of a continuous stretching surface with variable temperature. J. Heat transfer, V.107, pp.248-250 (1985)

[20] Gupta, P.S, Gupta, A.S : Heat and mass transfer on a stretching sheet with suction or blowing. Can. J. Chem. Eng., V.55, pp.744746(1977).

[21] Hsiao, K.L : Heat and mass transfer for electrical conducting mixed convection with radiation effect for visco elastic fluid past a stretching sheet. Journal of mechanics, Vol.24, No.2, pp.21-27(2008).

[22] Jat, R.N, Santosh Chaudhary : MHD flow and heat transfer over a stretching sheet, Applied Mathematical Sciences, Vol.3, No.26, pp.1285-1294 (2009).

[23] Magyari, E, Ali, M.E and Keller, B : Heat and mass transfer characteristics of the self-similar boundary layer flows induced by continuous surface stretched with rapidly decreasing velocities. Heat Mass Transfer, Vol.38, pp. 65-74 (2001).

[24] McLeod, J.B. and Rajagopal, K.R : On the uniqueness of flow of a Navier-Stokes fluid due to a stretching boundary. Arch. Ration. Mech. Anal., pp.98-386 (1987).

[25] Mohebujjaman, M, Tania, S. Khaleque and Samad, M.A : MHD heat transfer mixed convection flow along a vertical stretching sheet in presence of magnetic field with heat generation. International journal of Basic \& Applied Sciences, Vol.10, N0.2, pp.133142 (2007).

[26] Muthucumaraswamy, R. and Ganesan, P : On impulsive motion of a vertical plate with heat flux and diffusion of chemically reactive species. Forsch. Ingenieurwes, pp. 66-17 (2000).

[27] Raghavendra Rao : Mixed convective heat and mass transfer flow in channels and ducts. Ph.D Thesis, S.K.University, Anantapur, India (2012).

[28] Rana, M.A, Siddiqui, A.M and Ahmed, N : Hall effect on Hartmann flow and heat transfer of a burger's fluid. Phys. Letters A 372, pp. 562-568(2008).

[29] Raptis, A and Perdikis, C : Viscous flow over a non-linearly stretching sheet in the presence of a chemical reaction and magnetic field. Int. J. Non-linear Mechanics, Vol.41, pp.527-529 (2006).

[30] Sajid, M, Hayat, T and Asghar,S : Non-similar analytic solution for MHD flow and heat transfer in a third-order fluid over a stretching sheet. Int. J. of heat and mass transfer, Vol.50, pp.1723-1736 (2007).

[31] Sakiadis, B.C : Boundary layer behavior on continuous solid surfaces: I, Boundary layer equations for two-dimensional and axis symmetric flow, AICHE J., Vol.7, No.1, pp.7-28 (1961).

[32] Samad, M.A, Mohebujjaman, M : MHD heat and mass transfer free convection flow along a vertical stretching sheet in presence of magnetic field with heat generation. Research journal of Appl. Sciences, Engineering and technology, Vol.1, pp.98-106 (2009).

[33] Seddeek, M.A : Heat and mass transfer on a stretching sheet with a magnetic field in a visco-elastic fluid flow through a porous medium with heat source or sink. Computational Material Science, Vol.38, pp.781-787(2007).

[34] Shit, G.C : Hall Effects on MHD free convective flow and mass transfer over a stretching sheet. Int. J. of Appl. Math. and Mech., Vol.5, No.8, pp.22-38 (2009).

[35] Vajravelu, K. and Hadinicolaou, A : Convective heat transfer in an electrically conducting fluid at a stretching surface with uniform free stream. Int. J. Eng. Sci., Vol.35 pp.1237-1244 (1997).

[36] Veena, P.H, Pravin, V.K, Shahjahan, S.M and Hippargi,V.B : Non-similar solutions for heat and mass transfer flow in an electrically conducting Visco- Elastic fluid over a stretching sheet embedded in a porous medium. Int. J. of Modern Mathematics, Vol.2, No.1, pp.9-26 (2007).

[37] Watanabe T and Pop I, 1995. Hall effects on magnetohydrodynamic boundary layer flow over a continuous moving flat plate. Acta Mech. 108, pp. 35-47. 